https://doi.org/10.22364/hssl.26.1.2

\title{
IMPACT OF DISTANCE COMMUNICATION ON DIFFERENT MOTIVATIONAL CONCEPTS ${ }^{1}$
}

\author{
Frank W. Hager \\ Dipl.-Wirt.-Ing. (FH), MBA, M.A.
}

\begin{abstract}
This article should contribute to corporate communication theory by considering the mechanisms of distance communication (telecommuting) between mobile teleworkers and their organisation, as well as the role of a functional communication on both; the factual and relationship level in enhancing employee motivation. Despite its importance for organisations and leaders, there is considerable confusion about effects on motivation, associated with distance communication in the context of mobile telework. This article aims to provide a degree of clarity by identifying, analysing and discussing the main linkages to employee motivation found in general and relevant science literature, as well as scientific publications in common databases, to stimulate and provide directions for future research. Corporate communication and motivation literature, as well as scientific papers in this field has not yet adequately considered this concept. This may be due to confusion regarding to the definition of motivation, and to concerns about overlaps with related constructs such as engagement, organisational commitment, organisational identification or affiliation. This article closes the gap with an appropriate model, mirroring the found main concepts and enhancers of employee motivation as well as the associated communication effort on different "integration levels". The article discusses linkages between motivation and distance communication, which suggest research potential in the field of HR-Management and Organisational Development (OD). The study just as well encourages communicators in telework-teams, to consider effects of communication strategies and tactics. The aim of this analysis is also to inspire responsible person and departments to show up the communication needs of employees in mobile telework. This conceptual article provides an overview of motivation and communication theory literature, aiming to identify the main aspects for motivated employees. It suggests motivation as a hierarchical psychological state on different levels, of how strong employees in mobile telework are linked to and integrated into their organisation, against the background of distance communication.
\end{abstract}

Keywords: Mobile telework, telecommuting, distance communication, motivation, identifi-cation, commitment, affiliation

1 A version of this article was presented at the $21^{\text {st }}$ European Scientific Conference of Doctoral Students PEFnet 2017, November 30, 2017, Brno, Czech Republic. 


\section{Introduction}

Modern information and communication technologies bridged space and time in a way, considered hardly conceivable some years ago. This fact created completely new possibilities for work organisations. A cooperation or "working together", in a central enterprise is less and less necessary. In addition, the technology enables a previously unknown networking of organisations (Eichenlaub, 2010). The predominantly digital exchange in mobile telework, e.g. via Customer Relationship Management (CRM) Systems, Enterprise Resource Planning (ERP) - Systems and E-mail, as well as the brief exchange of information via smartphones, is the consequence of this development. From the perspective of the company, the deployment of mobile teleworkers is indispensable. On the one hand, due to the rapid reactivity to customer requirements, which lead to an increase in flexibility and thus to productivity and competitiveness (Nerdinger et al., 2011). On the other hand, companies hope to strengthen their innovative power and improve product quality, if mobile teleworkers are in regular personal contact with customers. Another attractive feature for companies are the reduced space requirements and the associated cost reduction potential (Bernardino, 1996; Berth, 1995). At the first glance, this decentralised form of work - away from their headquarters - offer employees the highest level of freedom and autonomy in the context of mobile telework. Due to the limited communication possibilities, in interaction between teleworkers and internal teams, or other parts of the company, characterised by the lack of social contacts with colleagues and executives, new problems arise in an organisational cooperation, which ultimately can make itself felt in terms of work performance and motivation.

\section{Results of the literature review}

The idea behind this study is the basic thought that a substitution of direct, personal communication by means of a digital or verbal goal- and purpose-oriented exchange via data processing systems, e-mail or short telephone conversations leads to the restriction of important qualities of human communication. This interpretation can be explained on the basis of the $2^{\text {nd }}$ Axiom of Watzlawick et al. (1967). Accordingly, each message contains information, whose content seems at the first sight rather uninteresting, because the nonverbal portion of the message provides the actual indication, of how the sender wishes to be understood by the recipient. In this respect, communication proceeds, according to Watzlawick et al. (1990), on a factual level and subliminally on a relationship level. The topic and content is communicated on the factual level; however, communication on the relationship level is more complex. The 
relationship aspect indicates how the transmitted data on the factual level is to be understood and represents a meta-communication - a higher-level communication. Furthermore, the thesis of Watzlawick et al. (1990), states, that the relationship level has a stronger influence on communication than the factual level. Thus, the relationship level also has a great impact on the factual portion of the message, while conversely the influence has a lesser extent (Reich, 2000). Speaking of a functional communication, it must succeed on both levels (Fulk \& Cummings, 1984). In the case of distancecommunication, which is mainly carried out via new media, and is not or only rarely characterised by face-to-face contacts, the relationship aspects are largely hidden. A contextless and abstract process thinking increasingly dominate communication, in this case, which does not additionally happen as a meta-communication, by exchanging information solely.

\section{Motivation in the understanding of this analysis}

In general, and without defining the term down to the most minute detail in this study, one speaks of motivation if a change in human behaviour because of a positively evaluated state of life can be noticed (Rheinberg, 2002). Internal and external incentives inducing individuals to this particular behaviour (Pelz, 2003; Jost, 2000, Comelli \& von Rosenstiel, 2009). It is spoken of motivation, if behaviour is targeted or determined: for example, in terms of reaching a certain goal or fulfilling important tasks. (Deci \& Ryan, 1993; Mook, 1996). The concept of motivation in this study implies the factors of intrinsic motivation (e.g. recognition, self-growth, control and warm relationships) and extrinsic motivation (e.g. safety, social status, good working conditions and salary) (Ryan \& Deci, 2000).

Against the background of employee motivation, the concepts 1) organisational commitment, 2) organisational identification, 3) organisational inclusion, and 4) affiliation has been identified as the main concepts of motivation in communication and interaction processes from the abundance of researched literature and scientific work. The analysis and discussion of the linkages between distance communication and motivation is given in the following explanations.

\section{Identification \& Commitment vs. Distance Communication}

By reviewing the relevant scientific literature and papers in the field of motivation and communication theory, the concepts of identification and commitment occurred frequently and partially overlapping. However, both terms should be considered in the following explanations in a differentiated way, in order to be able to define the relation to "distance communication" as precisely as possible. 
Nakra (2006) describes identification as follows: "Organisational Identification is one of the forms of an individual's attachment to an organisation that has been recognised as having important implications for organisational effectiveness". Ashforth and Mael (1989) argue that employees who identify strongly with their company tend to show a supportive attitude. Identification is, from their point of view, the perception of one's own person in relation to the company. Simon (1997) extends this statement and argues that employees who are strongly identified with their enterprise make decisions, which are consistent with the organisational objectives. Thus, companies benefit from strong organisational identification of their employees. The identification effect of internal communication between companies and employees therefore means, "[to] establish, and maintain mutually beneficial relationships between the organisation and the employees on whom its success or failure depends" (Cutlip et al., 1985). The importance of identification with regard to employee communication also plays a crucial role in the study by Smidts et al. (2001), who summarise that managers should promote internal communication, and thereby the strengthening of organisational identification. The importance of identification with one's own company is, from their point of view, often underestimated by the company's management. The results of the study by Smidts et al. (2001) clearly show that adequate information about the company strengthens identification. A good communication climate is achieved by providing sufficient information, opportunities to talk and the chance to be heard and actively involved. As a result, withheld information has a negative impact on identification (Welch, 2012).

Nakra (2006) clearly distinguishes between identification and commitment. The author believes, that identification describes the analysis of the relationship between individual and organisation, since identification also contains conclusions about the process and the product of the relationship. Commitment, on the other hand, tends to focus on something that an employee has done before or has done at a given time. Tompkins (1987) describes the difference between the two concepts as follows: identification is the substance of the relationship between the organisation and the individual, commitment corresponds to the form. Elements of the form could be, for example, loyalty to the organisation, the willingness to work hard for the employer or the intent to stay with the company (Wells, Thelen \& Ruark, 2007). In the same way, Mowday et al. (1979) consider it to be proven that commitment is correlated with a strong intrinsic motivation. Commitment develops as a result of an exchange-based relationship between individual and organisation (Mael \& Ashforth, 1992), in which the employee perceives himself/herself and his/her company as two separate psychological units (Rousseau \& Parks, 1993; Levinson, 1965). 
Mael \& Ashfort (1995) also found, that commitment could occur in a company-independent case. This way, an employee can build an emotional relationship with a company, which embodies similar goals and values, even without working there. In this respect, a person is experiencing commitment without being in direct interaction with the company.

Internal communication and organisational identification are strongly linked, as scientific studies show that communication affects the attitude of employees, which is in turn bound to the identification with the company (Nakra, 2006). Thus, communication can positively influence the identification process, as it allows employees to share subjective perception of the visions, goals and culture of the organisation (Bartels, Pruyn \& de Jong, 2009). Postmes et al. (2001) also echo this. In their opinion, vertical communication, which originates from the management and executive board, is the best way to influence organisational identification of employees. Vertical communication helps staff members to define themselves with the values of the organisation, its less tied to specific character traits of members and thus presents the organisation as a whole. Consequently, a sense of organisational attachment can be conveyed.

In the ideal case of a functional communication, this feeling feeds the perception of actively participating and shaping the organisation. Finally, a poor (or very limited) communication can weaken the organisational identification. Does the employee identify with the higher meaning of his/her work? Does the employee identify with his/her organisational role? Does the employee identify with the goals and is he/she willing to contribute to the achievement? It is obvious that these sources of motivation actually corresponding with organisational identification. It can be reasonably assumed, that employees, who identify themselves in some way with their work, with the purpose of their work and the organisation, are motivated - in the opposite case, without motivation, the willingness to perform is non-existent.

In the light of the foregoing considerations, it becomes clear, that organisational commitment and organisational identification should be distinguished conceptually. In conclusion, this distinction also refers to the degree of employee integration. The difference can be determined by the link to a person's self-concept (van Knippenberg \& Sleebos, 2006). Identification is part of an employee's self-concept. Commitment, on the other hand, is not necessarily connected with a person's self-concept (Ashforth \& Mael, 1989). Thus, an organisational identification represents a higher organisational bonding, reflecting at the same time the selfperception of the employees. Otherwise, commitment is a more general attitude (in a sense of bonding) of individuals. In other words, organisational identification could be regarded as a higher level of integration compared to commitment. 
These findings so far already show the importance of thinking about how the nature of communication, communication processes and communication channels affect the co-operation and motivation of employees. It can be assumed that the creation of conditions for higher organisational identification require a higher communication effort than for the creation of conditions for an organisational commitment of employees.

Whilst information and persuasive arguments are communicated by the management during the development of commitment, which in sum makes a job or the company interesting and valuable (van Dick 2004), the improvement of identification is about the creation of a sense of unity employees should know themselves as a part of the company. There are also internalisations of common objectives within identification processes taking place. Employees make organisational goals to their own, thereby contributing to the success of the company. In identification processes, staff members and the organisation merge to one psychological unit (Rousseau \& Parks, 1993; Levinson, 1965). Despite the exchange of information of the management on a factual level solely (Watzlawick et al., 1990) - in the context of vertical communication - motivational conditions

are not given, because of the spatially separate cooperation and the lack of structural integration.

\section{Organisational Inclusion vs. Distance Communication}

Lombard \& Ditton (1997) and Gajendran \& Harrison (2007) point out, that representatives in mobile telework often feel excluded, because they do not directly recognise how their daily work contribute to the objectives of their team or the company's aims. Bartel et al. (2007) report in a qualitative study from similar findings.

Buissing \& Broome (1999) note that the lack of information and a lack of transparency in relation to one's own company can cause the aforementioned uncertainties among teleworkers. In particular, they refer to the perception of their own work performance. This lack of perception is also mentioned by (Brandt, 1999), who argues, that successes in distance cooperation cannot be spontaneously shared with colleagues. In the opposite case, there are no immediate contacts to be able to clarify questions and problems. On the basis of these results it can be stated, that the direct, communicative reflection of work results, the perception, and in consequence the organisational sense of belonging could influence the employees motivation positively. Reversely seen, the lack of direct contacts for a constructive exchange leads to frustration.

Hence, distance communication can result in a lack of involvement of mobile teleworkers in organisational culture. Thomas (2005) describes 
organisational culture as an orientation system that reflects symbols, language, rituals or habits of the collective on the relationship level. In this framework of action, it is possible for employees to find their way around in the collective, for which knowledge about the social environment is needed and the knowledge of how to deal with this knowledge. Against this background, cultural norms or customs are a clear guidance, which directly influence the thinking, action and the perception of the workforce. Thus, organisational culture reflects what is right or wrong, good or bad and what kind of values and traditions should be lived and cultivated. Organisational culture, as it is linked to verbal and non-verbal communication, can be perceived in any place and at any time within the company, and characterises work processes (Strobel \& Lehning, 2003; Brunelle, 2013).

Based on this, the concept of the social anomie after Durkheim $(1983 / 1897)$ plays a decisive role in teleworking. Durkheim sees anomie as a state of social disintegration. Due to the borderless working situation, societal differentiation are becoming increasingly apparent. The absence of structural and regulatory principles weakens collegial cohesion. As a result, general social rules getting less attention, the collective order is dissolved, and a state of anomie appears. According to this, alienation the lack of tried and tested norms (in the context of this work: the nonperception of culture) - can be regarded as the opposite of organisational inclusion. Kanungo (1979) interprets the concept of alienation in a sociopsychological way. According to Maslow (1954), he describes it as unsatisfied or frustrated needs for safety and social inclusion. On the organisational and individual level, the study of alienation processes refer to their linkages to individual freedoms and control opportunities, possibilities for participation, responsibility, social integration and identification.

The subjective estrangement approach after Seeman $(1959,1972)$ differentiates five subjective psychological dimensions of alienation, which are derived from situational characteristics of the organisational environment. The characteristics of powerlessness and meaninglessness signify perceived control and influence limitations of individuals in social systems, as well as experienced meaninglessness - as a result of missing possibilities for recognising or expanding the conceptual connections between one's own work and the overall system, respectively for the lack of possibilities, to build or expanding competencies for these purposes.

If existing norms are no longer considered as the guiding basis for their own behaviour and are no longer shared with other individuals of the system, the individual who rejects the values and norms of society can perceive his/her cultural alienation through social learning processes. Seeman speaks here of the characteristics normlessness and value isolation. 
The characteristic self-estrangement describes alienation tendencies, which arise through lack of self-actualisation. ${ }^{2}$

Distance communication, perception of work performance and organisational culture are closely related to organisational inclusion respectively alienation. Lenk (1989) describes the fact that communication via technical media is not only narrowed, but also generally purposeoriented, hence, reduced to its factual value. Fulk \& Cummings (1984) also refer to Watzlawick et al. (1967) and agree that communication on a factual level loses its socially binding character. The holistic experience of the counterpart in the communication process remains incomplete. According to Lenk (1989), teleworking can suffer seriously in its quality due to limited communication.

This is understandable, since via Distance Communication usually a target-oriented and factual communication style is chosen. With an intensified use of electronic media, which neglects a personal face-to-face and informal communication style, this factual communication behaviour can on the long run cause the feeling of alienation. Establishing a functional communication on a factual and relationship level could thus reduce the discrepancy between the claims, norms and values, as well as the situational conditions of the work organisation, which oppose the individual needs. It is therefore important to integrate these values and needs of mobile teleworkers into the internal communication strategy and work routine. Hayes et al. (2002) also hold this view. They argue, that a better organisational integration of employees working at home means a strengthening of personal sense of belonging. The work of Baumeister \& Leary (1995), Golden (2006) and Greenhaus et al. (1990) examined the opposite case: The lack of organisational involvement of employees in workplaces outside the organisation is associated with reduced work engagement, dissatisfaction with work and a rejection of internal colleagues.

An integration of mobile teleworkers in the framework of an "extended communicative" culture ranges from uniform attitudes, in which the personality should be just as important as the staff qualification, through daily communication behaviours to the actual workplace beyond the organisation's boundaries and the technological prerequisites which determine the choice of communication channels. A holistic communicative experience has to be established, by supporting and carrying the organisational culture. It can be assumed that, by implementing this strategy, to ensure a higher quality of communication achieving a better

2 Maslow (1954) defines self-actualization as the desire or the tendency to exploit one's own full potential, the development of own personality. In doing so, the individual urges to experience his/her "full-being". 
integration of mobile teleworkers, the communication effort will continue to increase.

\section{Affiliation vs. Distance Communication}

Humans have the natural tendency, next to the needs for efficiency and autonomy, to adopt the regulation mechanisms of the social world unconsciously in order to be associated with other persons, becoming a member of the social world (affiliation). Attempting to feel connected with others, determining autonomously at the same time own actions, the person takes over and integrates goals and behavioural norms into his/her own self-concept. Prerequisites for this process are offers and requirements in an accepted environment, which strengthens the corresponding behavioural tendencies (Deci \& Ryan, 1993). Changes in membership status can cause emotional reactions. Positive effects are associated with higher affiliation; negative effects are associated with reduced affiliation. Furthermore, ongoing high involvement in social relations should lead to generally a better emotional condition; lasting deprivation, on the other hand, to a generally poorer emotional condition. These assumptions are evidenced by various studies, which show that happiness, contentment or serenity are associated with the existence of close social relationships, while a lack or loss of social relationships can be associated with feelings of anxiety, loneliness, and social isolation (Baumeister \& Tice, 1990; Leary, 1990; Leary, Koch \& Heckenbleikner, 2001; Leary \& Springer, 2001; Russel et al., 1984).

These findings can be easily projected to the context of mobile telework. For mobile teleworkers, a purely exchange on the factual level can lead to feelings of social isolation, if there are no compensating informal contacts with colleagues. Times for social communication are also required during working hours. If social contacts are neglected or not available, this has an impact on the working environment and the informal crisis management in every day work, which is normally able to determine many personal problems in operational cooperation (Walke, 1994). Brandt (1999) also considers that, especially in the form of telework, a subjective feeling of social isolation arises by the fact, that there is a serious reduction in social contacts at work. Telephone or electronic media could not adequately replace private or informal side conversations during coffee breaks or faceto-face meetings.

An affective bond and support, as well as emotional involvement, are essential in the field of teamwork, but harder to achieve if communication takes place over a structural distance. In addition, communication at a solely factual level is an obstacle, in order to express one's own emotions, which can lead into a higher stress level (Mann, 1998). Emotions are 
central for functional teamwork. They can benefit stirring interest in informal organisational processes (Ashforth \& Humphrey, 1995). The lack of personal links to other people and the lack of information in a social setting also affect, as pointed out by Gallenkamp et al. (2010), building a social relationship and trust. Cooper \& Kurland (2002) and Vega \& Brennan (2000) describe the perception of social isolation of employees in telework as one of the main problems of this form of labour. Montreuil \& Lippel (2003) speak behind this background of a critical disadvantage of telework. According to Baumeister \& Leary (1995), interpersonal relations are the basic need of every human being and responsible for human motivation.

Buddendieck et al. (1999) mention the need for self-motivation at telework. According to (Nerdinger \& Oelsnitz, 1995), it depends on the social connections of the mobile teleworkers to their colleagues. Conversely, it can be concluded that the feeling of social isolation, caused by a strongly restricted communication at a structural distance, can lead to low employee (self-) motivation. Emotional (and social) involvement are central to motivation (Ashforth \& Humprhrey, 1995; Organ, 1990). Mann et al. (2000) found, that the emotional part of teleworking and its impact on employees is focused on the absence of the physical organisation, the organisational structures and the work environment. Closely related to this is the physical separation of colleagues. This results in a reduction of the affective bonding of the team and in a lack of emotional support, as well as a loss of the meaningfulness of the communicated message. Also (Bakker, Van Emmerik \& Euwema, 2006) assume that group cohesiveness depends mainly on the affective bonding between employees. Emotions in the sense of contagion are part of the team spirit and can be a key driver in organisations (Mann et al., 2000).

Thus, for a motivated teleworker, there is a need to be emotionally integrated in a social network. Abraham Maslow describes this specific context on the basis of the need for love and affiliation at the third level of his model "Hierarchy of Needs" Maslow (1954). A social network can have the function of support, which is mainly determined by the quality of the system. The quality is, among other things, decisive, how much support a person receives from colleagues and direct supervisors, how often he/she is lonely and with which kind conflicts the employee is confronted (Döring, 2003). At this point, it is assumed that the quality of the social network is decisively determined by the quality of the communication.

In the light of the above-mentioned, it is clear that poor or limited communication bridging a structural distance and social isolation of mobile teleworkers - due to their affiliation needs - is closely linked to low staffmotivation. The research findings are mainly related to classic telework. However, it can be assumed, that the situation in mobile telework is similar. Social integration aiming at a feeling of employee's affiliation can 
be attained through a high level of horizontal communication effort, taking into account the needs of mobile teleworkers on a relationship level, in order to further increase staff motivation.

\section{Conceptual Model \& Discussion}

The previous discussion raises the question, how the relationship between distance communication and motivation of mobile teleworkers can be conceptualised. The model in Figure 1, in the form of a pyramid structure, contains the four main motivational concepts and motivators, identified in literature and discussed before, arranged within different levels of hierarchy attempting to link these against the background of Distance Communication. The motivation concepts are arranged in four categories, starting with the most basic physiological on the level of the organisation (bottom of the pyramid), which increase in their hierarchy and intensity up to cognitively and emotionally developed human needs for social affiliation.

The pyramid is a content model; it deals with content, nature and effect of the discussed and analysed motivational concepts. Furthermore, a taxonomy of the motivators is given, and finally it is concluded, by what communicative conditions which motivators become behavioural. In this respect, the phenomenon of distance communication on a factual level, has a higher negative effect on the behaviour on upper levels (and consequently on the integration of the employees) than on the lower levels.

The categories "organisational commitment" and "organisational identification" can be realised with comparatively lower (vertical) communication effort than a social integration of employees associated with the feeling of affiliation. The reason for this is the increasing need for communication on a relationship level, heading to the top of the pyramid. Responsible for this fact are related context information, which must be taken into account in the case of messages via distance communication, but which increase the individual effort in interactions. Thus, if an employee should feel social connectedness or affiliation and should be socially integrated, vertical communication is no longer sufficient, for example, within the scope of employee information activities.

Only by organisational inclusion, which is aiming perception and recognition of importance of the own work of the employees, a mobile teleworker becomes aware of the personal role in between the enterprise. This is achieved mainly by way of a horizontal communication, and through the involvement of the employee in the culture within the bounds of his/her organisation. In order to achieve a social cohesion, sharing of common values within teams and between colleagues, as well as 


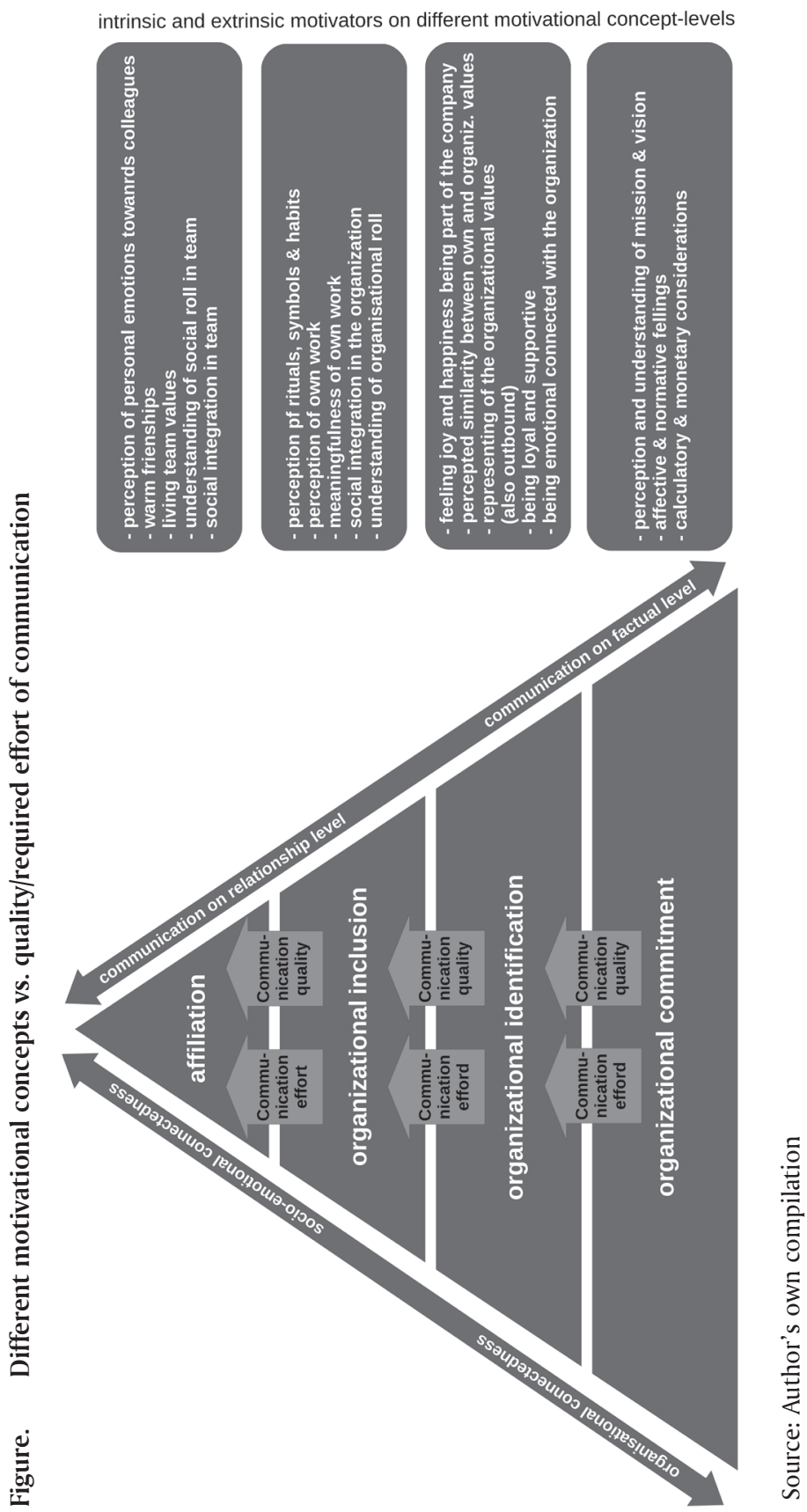


reaching the feeling of a sense of belonging, a functional and informal communication is necessary - on both the factual and the relationship level - which in turn counteracts an even higher individual communication effort by transporting additional context information on the part of the organisation, team members and supervisors equally.

Attributing the above-mentioned context information to a solely temporal effort is not reasonable. The higher communication effort also covers the avoidance of misinterpretations, wrong decisions, conflicts or the questioning of communication expectations, as well as the needs of employees in mobile telework. Those responsible in the departments of HR-management or organisational development (OD) are therefore required to consider these aspects within the communication strategy in teams and to question how, in addition to an objective-institutional communication, integrative communication tasks can be carried out via digital media.

Additional contextual information on the relationship level, which in some respects "simulate" a meta-communication at a distance, could thus contribute to an improvement in the motivation of the employees in telework. In order to achieve this, it is necessary to know individual motives and needs of employees at the remote workplace to get a clear idea of the contextual information required for an improved communication strategy.

\section{Conclusion}

The results of this study have implications for the selections of steps of the organisational development (OD), HR-Management and can show superiors' directions for the choice of virtual work programmes in the framework of mobile telework. In sum, this article explores the relationship between distance communication and different forms - respectively concepts - of motivation. The introduced Telework-Communication-Quality (TCQ) Model assumes a hierarchy of these major concepts and a rising communication effort, to achieve affiliation and, in this way, fully social integration of mobile teleworkers (represented by the top of the pyramid) into their organisation and teams. The communication effort can be seen or defined as a prerequisite reaching a higher communication quality on communication at a structural distance. Limited communication, which results from bridging this distance, can either been solved by emerging from the digital environment, coming more often into physical contact, in the form of meta-communication, or by simulating it, by adding specific context information to the daily exchange of digital messages or telephone calls. For example, semiotic studies could examine the influence of verbal and visual symbols on work engagement more precisely. But also the sound of communication (tone of voice), should examined in terms of its possible 
impact on the perception of personal needs of employees in telework, to find out, if there is a probability to achieve a higher motivation by intonation. This future works could be a giant leap in motivation research in the context of this article.

\section{REFERENCES}

1. Ashforth, B. E. \& Humphrey, R. H. 1995. Emotion in the Workplace: A Reappraisal. Human Relations, SAGE Publications, Thousand Oaks, 48. pp. 97-125.

2. Ashforth, B. E. \& Mael, F. A. 1989. Social identity and the organization. Academy of Management Review, 14(1), pp. 20-39.

3. Bakker, A. B., van Emmerik, I. J. H. \& Euwema, M. C. 2006. Crossover of burnout and engagement in work teams. Work and Occupations, SAGE Publications, Thousand Oaks, 33(4), pp. 464-489.

4. Bartel, C. A.; Wrzesniewski, A. \& Wiesenfeld, B. 2007. The struggle to establish organizational membership and identification in remote work contexts. In Bartel, C. A. (Ed.), Identity and the Modern Organization, Lawrence Erlbaum Associates, Mahwah, New Jersey, pp. 253-272.

5. Bartels, J.; Pruyn, A. \& De Jong, M. 2009. Employee identification before and after an internal merger: A longitudinal analysis. Journal of Occupational and Organizational Psychology, Wiley, New Jersey, 82, pp. 113-128.

6. Baumeister, R. R. \& Leary, M. R. 1995. The need to belong: Desire for interpersonal attachments as a fundamental human motivation. Psychological Bulletin, APA, Washington, 117, pp. 497-529.

7. Baumeister, R. F. \& Tice, D. M. 1990. Anxiety and social exclusion. Journal of Social and Clinical Psychology, New York, London, 9, pp. 165-195.

8. Bernardino, A. 1996. Telecommuting: Modeling the employers and the employee's de-cisionmaking process. Routledge, London, p. 9.

9. Berth, R. 1995. Nachholbedarf Personalentwicklung. In: Gablers Magazin, Wiesbaden, 12, pp. 37-39.

10. Brandt, C. 1999. Telearbeit - eine Zukunft für Frauen mit Kindern? In: Die Frau in unserer Zeit. Schriftenreihe der Konrad Adenauer Stiftung, Bonn, 2, p. 59.

11. Brunelle, E. 2013. Leadership and Mobile Working: The impact of distance on the Superior-Subordinate-Relationship and the moderating effects of Leadership style. International Journal of Business and Social Science, Radford, 4(11), pp. 1-14.

12. Buddendieck, A.; Leo, P. E. \& Hell, W. 1999. Introduction of alternating telework in a local government administration - an evaluation. Zeitschrift für Arbeits- und Organisationspsychologie, Hofgrefe, Göttingen, 43(3), pp. 165-170.

13. Büssing, A. \& Broome, P. 1999. Trust under telework. Zeitschrift für Arbeits- und Organisationspsychologie, Hofgrefe, Göttingen, 43, pp. 122-133.

14. Comelli, G. \& von Rosenstiel, L. 2009. Führung durch Motivation. Vahlen, München, p. 6.

15. Cooper, C. D. \& Kurland, N. B. 2002. Telecommuting, professional isolation and employee development in public and private organizations. Journal of Organizational Behavior, Wiley, New Jersey, 23, pp. 511-532. 
16. Cutlip, S. M.; Center, A. H. \& Broom, G. M. 1985. Effective public relations. PrenticeHall, Upper Saddle River, p. 215.

17. Deci, E. L. \& Ryan, R. M. 1993. The Theory of Self-Determination of Motivation and its Relevance to Pedagogics. In: Zeitschrift für Pädagogik, Berlin, 39(2), pp. 223-238.

18. Döring, N. 2003. Sozialpsychologie des Internet: Die Bedeutung des Internet für Kommunikationsprozesse, Identitäten, soziale Beziehungen und Gruppen. Hogrefe, Göttingen.

19. Durkheim, È. 1983 orig. 1897. Der Selbstmord. Suhrkamp, Frankfurkt. p. 329.

20. Eichenlaub, A. 2010. Vertrauensaufbau bei virtueller Kommunikation durch Ähnlich- keitswahrnehmung. Springer Gabler, Wiesbaden, p. 4.

21. Fulk, J. \& Cummings, T. G. 1984. Refocusing Leadership: A modest proposal. In: J. C. Hunt; D. M. Hosking; C. A. Schriescheim; R. Steward (Eds.), Leaders and Managers: International Perspectives on managerial Behavior and Leadership, Pergamon, Oxford, pp. 53-81.

22. Gajendran, R. S. \& Harrison, D. A. 2007. The good, the bad, and the unknown about telecommuting: a meta-analysis of the psychological mediators and individual consequences, Journal of Applied Psychology, APA, Washington, 92, pp. 1524-1541.

23. Gallenkamp, J.; Picot, A; Welpe, I. \& Drescher, M. 2010. Die Dynamik von Führung, Vertrauen und Konflikt in virtuellen Teams. In: Gruppendynamik und Organisationsberatung. Springer, Wiesbaden, 41(4), pp. 289-303.

24. Golden, T. D. 2006. Avoiding depletion in virtual work: Telework and the intervening impact of work exhaustion on commitment and turnover intentions. Journal of Vocational Behavior, Elsevier, Amsterdam, 69(1), pp. 176-187.

25. Greenhaus, J. H., Parasuraman, S. \& Wormley, W. M. 1990. Effects of Race on Organizational Experiences, Job-Performance Evaluations and Career Outcomes, Academy of Management Journal, Chicago, 33(1), pp. 64-86.

26. Hayes, B. C.; Hayes, S. A. \& Major, D. A. 2002: Climate for opportunity: a conceptual model. Human Resource Management Review, Elsevier, Amsterdam, 12, pp. 445-468.

27. Jost, P. 2000. Organisation und Motivation - Eine ökonomisch-psychologische Einfuih-rung. Springer, Gabler, Wiesbaden, pp. 80-83.

28. Kanungo, R. N. 1979. The concepts of alienation and involvement revisited. Psychological Bulletin, Washington DC, 86, pp. 119-138.

29. Leary, M. R. 1990. Responses to social exclusion: Social anxiety, jealousy, loneliness, depression, and low self-esteem. Journal of Social and Clinical Psychology, New York, London, 9, 221-229.

30. Leary, M. R., Koch, E. \& Hechenbleikner N. 2001. Emotional responses to interpersonal rejection. In: Leary M. R., (Ed.). Interpersonal rejection. Oxford University Press; New York: 2001. pp. 145-166.

31. Leary, M. R., \& Springer, C. 2001. Hurt feelings: The neglected emotion. In R. M. Kowalski (Ed.), Aversive behaviors and relational transgressions: The underbelly of social interaction. American Psychological Association, Washington, pp. 151-175. 
32. Lenk, T. 1989. Telearbeit. Möglichkeiten und Grenzen einer telekommunikativen De-zentralisierung von betrieblichen Arbeitsplätzen, Duncker \& Humblot, Berlin, p. 103.

33. Levinson, H. (1965). Reciprocation: The relationship between man and organization. Administrative Science Quarterly, SAGE Publications, Thousand Oaks, 9, pp. 370-390.

34. Lombard, M. \& Ditton, T. 1997. At the Heart of It All: The Concept of Presence. Journal of Computer-Mediated Communication, Wiley, New Jersey, 3(2).

35. Mael, F. A. \& Ashforth B. E. 1992. Alumni and their alma mater: A partial test of the reformulated model of organizational identification. Journal of Organizational Behavior, Wiley, New Jersey, 13, pp. 103-123.

36. Mann, S. 1998. Achieving frontline communication excellence: The cost to health. IEEE Transactions on Professional Communication, New York, 41, pp. 254-265.

37. Mann, S.; Varey, R.; Button, W. 2000. An exploration of the emotional impact of tele-working via computer-mediated communication. Journal of Managerial Psychology, Bingley, 15, pp. 668-690.

38. Montreuil, S. \& Lippel, K. 2003. Telework and occupational health: a Quebec empirical study and regulatory implications. Safety Science, Elsevier, Amsterdam, 41, pp. 339-359.

39. Maslow, A. H. 1954. Motivation and personality. Harper and Row, New York.

40. Mook, D. G. 1996. Motivation - The Organization of Action W. W. Norton, New York, pp. 25-53.

41. Mowday, R. T.; Steers, R. M. \& Porter, L. W. 1979. The Measurement of Organizational Commitment. Journal of Vocational Behavior, Elsevier, Amsterdam, 14, pp. 224-247.

42. Nakara, R. 2006. Relationship between communication satisfaction and organizational identification: An empirical study vision. The Journal of Business Perspective, SAGE Publications, Thousand Oaks, 10(2), pp. 41-51.

43. Nerdinger, F. W.; Blickle, G.; Schaper, N. 2011. Arbeits- und Organisationspsychologie. Springer, Berlin, Heidelberg, p. 506.

44. Nerdinger, F. W. \& Von Oelsnitz, D. 2008. Grundlagen des Verhaltens in Organisationen. Kohlhammer, Stuttgart, p. 102.

45. Organ, D. W. 1990. The motivational basis of organizational citizenship behavior. In. L. L. Cummings, \& B. W. Staw (Eds.), Research in Organizational Behavior, Greenwich, JAI Press, 12, pp. 43-72.

46. Pelz, W. 2004. Kompetent fuihren. Springer, Wiesbaden, p. 117.

47. Postmes, T., Tanis, M. \& De Wit, B. 2001. Communication and commitment in organizations: A social identity approach. Group Processes \& Intergroup Relations, SAGE Publications, Thousand Oaks, 4(3), pp. 227-246.

48. Reich, K. 2000. Systemisch-konstruktivistische Pädagogik. Einführung in Grundlagen einer interaktionistisch-konstruktivistischen Pädagogik. Luchterhand, Neuwied, p. 35.

49. Rheinberg, F. 2002. Motivation. Kohlhammer, Stuttgart, p. 17.

50. Rousseau, D. M. \& Parks, J. M. 1993. The contracts of individuals and organizations. In L. L. Cummings and B. M. Staw (Eds.), Research in Organizational Behavior, JAI Press, Greenwich, 15, pp. 1-47. 
51. Russell, D.; Cutrona, C. E., Rose, J.; Yurko, K. 1984. Social and emotional loneliness: An examination of Weiss's typology of loneliness. Journal of Personality and Social Psychology, 46, pp. 1313-1321.

52. Ryan, M. \& Deci, E. L. 2000. Intrinsic and Extrinsic Motivation: Classic Definitions and new directions. Contemporary Educational Psychology, Elsevier, Amsterdam, 25, pp. 54-67.

53. Seeman, M. 1959. On the meaning of alienation. American Sociological Review, SAGE Publications, Thousand Oaks, 24, pp. 783-791.

54. Seeman, M. 1972. Alianation an engagement. In: A. Campbell \& P. H. E. Converse (Eds.), The human meaning of social change, Russell SAGE Foundation, New York, pp. 472-527.

55. Simon, H. A. (1997). Administrative behavior: A study of decision-making processes in administrative organizations. Free Press, New York, 33, pp. 355-367.

56. Smidts, A.; Pruyn, A. \& Van Riel, C. 2001. The impact of employee communication and perceived external prestige on organizational identification. Academy of Mana-gement Journal, Chicago, 49(5), pp. 1051-1062.

57. Strobel, G. \& Lehning, U. 2003. Arbeitssituation von Beschäftigten im Außendienst: Defizite und Gestaltungsmöglichkeiten der psychosozialen Arbeitsbedingungen. Bun-desanstalt fuir Arbeitsschutz und Arbeitsmedizin, Dortmund, Berlin, Dresden.

58. Thomas, A. 2005. Kultur und Kulturstandards. In: Thomas, A.; Kinast, E.-U.; SchrollMachl, S. (Ed.): Handbuch Interkulturelle Kommunikation und Kooperation, Grundlagen und Praxisfelder, Vandenhoeck \& Ruprecht, Göttingen, pp. 19-31.

59. Tompkins, P. K. 1987. Translating organizational theory: Symbolism over substance. In Jablin, F. M., Putnam, L. L., Roberts, K. H. \& Porters, L. W. (Eds.). Handbook of organizational communication: An interdisciplinary perspective. SAGE Publications, Thousand Oaks, pp. 70-96.

60. Van Dick, R. 2004. Commitment und Identifikation mit Organisationen. Hogrefe, Göttingen, p. 5.

61. Van Knippenberg, D. \& Sleebos, E. 2006. Organizational identification versus organizational commitment: self-definition, social exchange, and job attitudes. Journal of Organizational Behavior, Wiley, New Jersey, 27, pp. 571-584.

62. Walke, B. 1994. Betriebliche und überbetriebliche Vernetzung von Arbeitsplätzen. Springer Gabler, Wiesbaden, p. 233.

63. Watzlawick, P.; Beavin, J. H. \& Jackson, D. D. 1967. The Pragmatics of Human Communication, W. W. Norton \& Co., New York.

64. Watzlawick, P.; Beavin, J. H. \& Jackson, D. D. 1990. Menschliche Kommunikation: Formen, Störungen, Paradoxien. Huber, Bern, Stuttgart, Wien, pp. 53-56.

65. Welch, M. 2012. Appropriateness and acceptability: Employee perspectives of in-ternal communication. Public Relations Review, Elsevier, Amsterdam, 38, pp. 246-254.

66. Wells, M. M.; Thelen, L. \& Ruark, J. 2007. Workspace personalization and organizational culture. Does your workspace reflect you or your Company. Environment and Behavior, SAGE Publications, Thousand Oaks, 39(5), pp. 616-636.

67. Vega, G.; Brennan, L. 2000. Isolation and technology - The human disconnect. Journal of organizational change management, Emerald Insight, Bingley, 13, pp. $468-481$. 